\title{
Vision, Big Data, and the Allegory of the Cave
}

\author{
Kurt Stuke \\ Adjunct-Organizational Leadership, Southern New Hampshire University, Manchester, USA \\ Email: kurt@kurtstuke.com
}

Received 9 September 2015; accepted 16 October 2015; published 19 October 2015

Copyright (c) 2015 by author and Scientific Research Publishing Inc.

This work is licensed under the Creative Commons Attribution International License (CC BY). http://creativecommons.org/licenses/by/4.0/

(c) ()

\section{Abstract}

The importance of vision in guiding a leader and an organization is paramount. Given the importance of vision, leaders will often seek assistance from tools in order to amplify their vision. Big data is one of the primary tools commonly sought. In this brief article, the advantages and disadvantages of relying on big data are explored. Plato's allegory of the cave is used to advance the position that a proper vision ought to dwell in experience first and only secondarily resort to abstraction.

\section{Keywords}

\section{Vision, Plato, William James, Philosophy of Leadership}

\section{Introduction}

A leader's vision, to borrow from the American philosopher William James, is the great fact of that leader [1]. Vision is defined in many different ways but at the concept's fluid and emergent core dwells an ability to see what has not been seen previously. The sight may be incremental and afford a glimpse of how to improve the current-state or, in its most extreme instances, can be disruptive and may usher in a new state.

\section{The Amplification of Big Data}

Given the importance of vision, are there tools we can employ in order to amplify our vision? Big data is one tool sought commonly for this purpose. The lure is apparent; big data promises insights into even the most complex of issues. If vision is grounded in big data then the organization will gaze above the "messiness that names us alive" [2] to the higher ground of objectivity. Perhaps more importantly, big data augurs data-based probabilities, upon which, the future (with a high degree of confidence it is promised) will unfold. If we see it, we believe we can control it.

It is difficult to resist the aforementioned claims. The ability to use data like "winged concepts" [3] in order to see what was once obscured, and, to lend order to an unpredictable, emergent, and complex reality is, of course, 
highly desirable. But should we rest our vision in big data? Does big data, in all instances, improve a leader’s vision?

\section{Exploring the Cave}

Does big data deliver on its promises? That is, should we, as leaders, accept the lure of big data? We face a scenario similar to that of the prisoners within Plato's allegory of the cave [4]. The prisoners described within the allegory were chained in a cave and could see only the wall in front of them. A fire behind the prisoners cast shadows on the wall. The prisoners, as humans will do, made sense of reality through interpreting the data they were given. In this case, the data consisted of shadows.

One prisoner, after being freed, experienced the "bigger picture.” While living "topside," he moved from the coldness of abstraction to dwelling in the warmth of the sun. He returned to those still imprisoned to inform them of what he had learned. He asserted that they were mistaking shadows, pale abstractions of lived reality, for reality itself. The prisoner and his vision were rejected promptly. The equivalent of an organizational summary dismissal occurred and the prisoner vacated the premises while pursuing career opportunities elsewhere.

\section{Exploring Our Vision}

We desire typically to align ourselves with the freed prisoner, the seer of truth according to Plato, but where does our alignment reside truly? A vision overly-reliant upon big data is a vision grounded in abstraction. Big data may be used to "lay hold of our experiences and to co-ordinate them" [5] but a properly informed vision should dwell first in experience and refer to the static snap shots offered through big data secondarily. In short, a vision dependent upon big data faces the danger of being a vision informed by shadows.

When a vision is informed by shadows, we are prone to make assumptions such as leading is a type of knowing. By extension, the difference between leaders and followers is that leaders are experts, i.e. those who know, while followers, sadly, are ignorant. From this angle-of-vision, leadership proficiency may be measured in terms of the fluency of a leader's knowledge and how well the leader has subordinated his or her followers to the leader's (or the body of knowledge as set by a group of leaders) point-of-view. To lead, as defined through this view, is to control and command. Big data is a tool that can help a leader control the future; knowledge is instrumental in influencing followers in order to realize the goal of controlling the future.

As the vision is, by definition, murky, the difference between leader and follower is often applied beyond knowing; those who are positioned higher within the organization chart (a mere two-dimensional representation of reality, i.e. an abstraction) are perceived as not only knowing more, but, in some way, as being more. Perhaps caused by the ambiguity inherent within the vision, the information from the abstraction may be applied beyond the intended or original reference frame.

What is clear, even within a vision informed by shadows, is the assumption of disjunction within the organization or context of leadership. Knowers are seen as separate and distinct from that which is known, and, leaders are seen as separate and distinct from followers. In our most natural or discrete state, this vision asserts that we are all prisoners chained in place. We dwell in alienation. The framing of leadership as a top-down phenomenon is consistent with the assumption of alienation latent throughout the allegory and present within the aforementioned vision. The lionization of knowing seems consistent as well as the only mode of engagement open to those who remain imprisoned from the external world is one of knowing. Leadership, when cast through this vision, is better likened to a reading of the "cosmic drama" unfolding before us than to a writing and a righting of the drama as it unfolds.

\section{Conclusion}

What does the popularity of big data among leadership programs and among practitioners suggest? Are we more aligned with the freed prisoner or the group of prisoners that remain chained in place?

\section{References}

[1] James, W.H. (1977) A Pluralistic Universe. In: Bowers, F. and Skrupskelis, I.K., Eds., Harvard University Press, Cambridge.

[2] Wheatley, M.J. (2006) Leadership and the New Science: Discovering Order in a Chaotic World. 3rd Edition, Berrett- 
Koehler Publishers, Inc., San Francisco.

[3] James, W.H. (1977) A Pluralistic Universe. In: Bowers, F. and Skrupskelis, I.K., Eds., Harvard University Press, Cambridge.

[4] Plato and Reeve, C.D.C. (2004) Plato's the Republic. 3rd Edition, Hackett Publishing, Cambridge.

[5] James, W.H. (1977) A Pluralistic Universe. In: Bowers, F. and Skrupskelis, I.K., Eds., Harvard University Press, Cambridge. 